\title{
Empresas públicas y proyectos de desarrollo económico: los planes gubernamentales para la empresa Bodegas y Viñedos Giol (Mendoza, Argentina, 1954-1964)
}

\section{Public Enterprises and Economic Development Projects: Government Plans for the Company Bodegas y Viñedos Giol (Mendoza, Argentina, 1954-1964)}

Patricia Olguín 1, * iD 0000-0002-7388-2257

\begin{abstract}
${ }^{1}$ Consejo Nacional de Investigaciones Científicas y Técnicas, Instituto de Ciencias Humanas, Sociales y Ambientales, Mendoza, Argentina

* Correspondencia: polguin@mendoza-conicet.gob.ar
\end{abstract}

Resumen. El trabajo analiza los planes gubernamentales elaborados para una firma líder del mercado vitivinícola argentino. Se centra en los planes que propiciaron su compra por parte del estado de Mendoza en 1954 y que promovieron su transformación en un instrumento de regulación de precios e integración vertical de productores en 1964. Este estudio se inscribe en un debate más amplio relativo a la actuación de las empresas públicas industriales como impulsoras de proyectos de desarrollo económico en América Latina, y en Argentina. La hipótesis sostiene que, si bien las funciones empresariales reflejaron un amplio consenso, los mecanismos de implementación dependieron de la trayectoria de los funcionarios a cargo. Desde un enfoque de historia de empresas, se examinan fuentes públicas y privadas y se construyen indicadores cuantitativos sobre el desempeño agroindustrial.

CÓMO CITAR: Olguín, P. (2019). Empresas públicas y proyectos de desarrollo económico: los planes gubernamentales para la empresa Bodegas y Viñedos Giol (Mendoza, Argentina, 1954-1964). America Latina en la Historia Económica, 26(1), e952. DOI: 10.18232/alhe.925

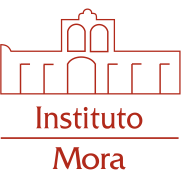


Palabras clave: empresas públicas; desarrollo económico; política industrial; vitivinicultura.

Abstract. The paper analyzes the government plans developed for a leading firm in the Argentine wine market. It focused on the plans that prompted its purchase by the State of Mendoza in 1954 and in those that promoted its transformation into an instrument of prices and vertical integration of producers in 1964. It is part of a broader discussion of the role played by industrial public enterprises as promoters of economic development projects in Latin America, and in Argentina. The hypothesis is that, if the business functions have a broad consensus, the implementation mechanisms depended on the trajectory of the officials in charge. From a business history approach, public and private sources are examined and quantitative indicators on agro-industrial performance are constructed.

Key words: public enterprises; economic development; industrial policy; wine industry.

JEL: H32; O1; L52; N8.

Recibido: 25 de septiembre de 2017.

Aceptado: 26 de febrero de 2018.

Publicado: 30 de julio de 2018.

Organismo colaborador: Consejo Nacional de Investigaciones Científicas y Técnicas, Instituto de Ciencias Humanas, Sociales y Ambientales, Mendoza, Argentina.

\section{INTRODUCCIÓN}

El objetivo del trabajo es analizar los proyectos gubernamentales elaborados para una empresa líder del mercado vitivinícola argentino: la Sociedad Anónima Bodegas y Viñedos Giol (en adelante Bodegas Giol). Se centra en los planes económicos y financieros que propiciaron su compra por parte del estado de Mendoza en 1954 y en aquellos que promovieron su transformación en un instrumento provincial de regulación de los precios del vino y de integración vertical de productores en 1964. Este estudio pretende contribuir al debate en torno a la actuación de las empresas públicas industriales como impulsoras de proyectos de desarrollo económico en América Latina, y en Argentina durante el tercer cuarto del siglo xx. Esto es, en una etapa signada por la conflictividad política, la inestabilidad en los indicadores económicos y los cambios en la orientación de la política económica.

Los balances sobre el estado del conocimiento en historia de empresas han destacado la incidencia del Estado en el desarrollo económico y social de América Latina; el cual, incluso, en algunos países, como Argentina, ha dado lugar al término Estado empresario (Barbero y Jacob, 2008; Dávila, 2013, p. 113; García, 2007). De hecho, el ámbito de influencia de las empresas públicas 1 se expandió desde los sectores tradicionales de intervención estatal (infraestructura, comunicaciones, energía, finanzas) hacia el industrial y urbano, ocupando posiciones predominantes en sectores estratégicos para la competitividad de la economía, así como importancia en la generación de empleo y la inversión en capital (Labrador, 2015, p. 13). En Argentina, luego de la finalización de la segunda guerra mundial, y coincidentemente con el advenimiento del peronismo, tuvo lugar una gran ampliación del Estado empresario, en la que este asumió el relevo del capital extranjero. En las décadas de 1950 y 1960 se produjo un reacomodamiento de la función

\footnotetext{
${ }^{1}$ Concepto amplio de empresa pública que incluye a todas las organizaciones económicas productoras de bienes o servicios, de propiedad pública total o parcial o de control estatal (Martín Aceña y Comín, 1990).
} 
del Estado, el cual amplió su presencia en algunos sectores económicos -como el industrial-, y la redujo en otros. El incremento de tamaño se advirtió no sólo a escala nacional, sino también subnacional (provincial), ya que, en muchos casos, el mismo estuvo motivado por conflictos sociales surgidos a partir de las dificultades que atravesaban las economías regionales (Regalsky y Rougier, 2015, pp. 10-11 y 386-387). La estructuración del país en un Estado federal con estados provinciales autónomos habilitó a los gobiernos locales a asumir funciones empresariales con fines económicos, políticos y sociales. Este fue el caso de las operaciones de intervención estatal realizadas por la empresa Bodegas y Viñedos Giol en los mercados de uvas y vinos de Mendoza durante crisis de sobreproducción de vinos en las décadas de 1960, 1970 y 1980 (Olguín, 2013b) ${ }^{2}$

Bodegas Giol fue utilizada, desde su incorporación al estado provincial, como un instrumento de política pública para emprender la diversificación de la matriz productiva de Mendoza y, entre tanto, regular el mercado vitivinícola. Se trataba de reducir el peso específico de esa agroindustria en la economía provincial y disminuir su inestabilidad, por cuanto los vaivenes de la actividad impactaban negativamente en el producto bruto geográfico y las finanzas públicas. A través de la firma se intentó, entonces, estimular el desarrollo de otras industrias de base minera y agraria y enfrentar algunos de los problemas estructurales que venían afectando a la vitivinicultura desde fines del siglo XIX. Al respecto, cabe mencionar que el vino, en su mayoría del tipo de mesa, era elaborado en los oasis de las provincias de Mendoza y San Juan por pequeños y medianos viñateros, cooperativas, bodegueros trasladistas (que ofrecían su producción en el mercado mayorista) y, en menor medida, grandes bodegas integradas. Luego, el vino a granel, adquirido en los mercados mayoristas, era despachado en toneles y tanques por medio del ferrocarril y flotas de camiones hacia las plantas de fraccionamiento localizadas en Buenos Aires, Santa Fe, Córdoba y el resto del país. Allí era envasado, en su mayor parte en botellas, y vendido a distribuidores y comerciantes mayoristas quienes, a su vez, lo comercializaban en los canales minoristas a fin de satisfacer las necesidades de consumo de los inmigrantes europeos y sus familias (Olguín, 2015a y b).

Los desfasajes periódicos entre la oferta y la demanda de vinos derivaron en etapas de sobreproducción o infraconsumo. Durante las coyunturas críticas, el abuso de posición dominante por parte de las grandes firmas industriales y comerciales agravaba la situación de los pequeños y medianos productores. En efecto, la actividad había crecido aceleradamente bajo el impulso de la promoción estatal, ignorando las debilidades advertidas por los expertos: la expansión indiscriminada del área cultivada con vid, la reducida diversificación de los usos de la uva, la dificultad de acceso al crédito, la escasa integración vertical de las etapas agrícola, industrial y comercial, los elevados costos de transporte, la adulteración del vino por deficiencias en los controles, la falta de propaganda al consumo interno de vinos y la casi inexistente exportación de productos vitivinícolas. De esta forma, la inestabilidad en los precios de la uva y el vino y las pujas distributivas entre los eslabones de la cadena de valor fueron los rasgos distintivos del sector hasta fines de la centuria. Las causas y los efectos de la crisis fueron atacados por un conjunto de políticas públicas nacionales y provinciales, con frecuencia en respuesta a los reclamos de las asociaciones empresariales (Azpiazu y Basualdo, 2001; Balán, 1978; Balán y López, 1977; Barrio, 2002, 2010; Coria, 2010; Díaz, 1982; Fleming, 1979; Mateu, 2002, 2014; Mateu y Olguín, 2006; Mateu y Stein, 2008; Olguín, 2015b; Olguín y Mellado, 2006; Richard, 1998, 2000, 2008; Richard y Pérez, 1994).

\footnotetext{
${ }^{2}$ Sobre las empresas públicas, véanse Barbero (2006), Schvarzer (2006), García Heras (2007), Barbero y Jacob (2008), Guajardo y Labrador (2015). Sobre el caso argentino, véanse, a modo de ejemplo, Rougier (2007, 2010,2011 y 2013), Belini y Rougier (2008), Regalsky (2010), Regalsky y Rougier (2015).
} 
El enfoque utilizado en esta investigación prioriza a la empresa como unidad de análisis, en el marco de las contribuciones que la historia de empresas ha realizado al campo de la historia económica. En la historiografía latinoamericana han prevalecido los enfoques macroeconómicos y formalistas en relación con el análisis sobre la intervención estatal en la economía, colocando menor énfasis en el conocimiento sobre la historia de la administración pública y los organismos encargados de aplicar políticas, como ministerios, secretarías, agencias y, en especial, las empresas públicas (Guajardo, 2015, p. 23). Sin embargo, estas últimas han sido reconocidas como espacios relevantes para explorar el diseño de las políticas y su aplicación, y la función que distintos sujetos, con intereses públicos y privados, asumieron en esos procesos. En este sentido, trabajos recientes sobre la experiencia argentina han destacado que, en tanto empresa, este tipo de organización desarrolla su producción de bienes y servicios para el mercado y, en tanto pública, se encuentra sujeta a consideraciones de bienestar público, bajo la influencia de burócratas, políticos y consumidores (Regalsky y Rougier, 2015, p. 15).

Justamente por su carácter de empresa pública -y, particularmente, de tipo estatal-, la experiencia de Bodegas Giol fue singular. Su condición le permitió obtener crédito oficial a tasas preferenciales para financiar operaciones de compra de grandes volúmenes de uvas y vinos en los mercados locales (iniciadas en 1964) y la prestación del servicio de elaboración para terceros (que comenzaría en 1967). De modo que, a fin de sopesar los planes propuestos para la firma, resulta conveniente prestar atención, someramente, a las cooperativas vitivinícolas formadas al amparo del Departamento de Cooperativas de Mendoza luego de 1953 y, especialmente, a la sociedad de capital mixto (público y privado) llamada Corporación Agroeconómica, Vitivinícola, Industrial y Comercial (CAVIC) y fundada en la provincia de San Juan en 1964 (Olguín, 2013a). En el plano internacional, interesa considerar la expansión de las bodegas cooperativas españolas bajo el estímulo estatal del régimen franquista en las décadas de 1950 y 1960 (Medina-Albaladejo, 2016).

La hipótesis que se intenta demostrar sostiene que las funciones empresariales asignadas a Bodegas Giol reflejaron un amplio consenso político y empresarial fundado en objetivos similares de desarrollo económico y social, tanto en 1954 como en 1964; en cambio, sus mecanismos de implementación dependieron de las trayectorias académicas y profesionales de los funcionarios encargados de su diseño y ejecución. Para ello, el trabajo se vale de un conjunto de fuentes de información relativas a los planes elaborados para Bodegas Giol, y los funcionarios que intervinieron en esas iniciativas (Plotkin y Zimmermann, 2012). Las mismas consisten en memorias empresariales, discursos de gobernadores, reseñas de gestión gubernamental, diarios de sesiones legislativas y obras de época. Asimismo, se han consultado estadísticas oficiales, a fin de construir algunos indicadores cuantitativos sobre los volúmenes de producción y consumo de vino y los precios de la uva y el vino en la agroindustria vitivinícola mendocina, y la prensa local.

El trabajo se organiza en dos partes. La primera, estudia el proyecto económico y político que impulsó la compra de la firma en 1954. La segunda, examina la propuesta oficial que intentó otorgarle un lugar activo en la integración de la cadena vitivinícola y la regulación de los precios de vino en 1964. Por último, se presentan las reflexiones finales y las referencias bibliográficas.

\section{EL PROYECTO DE LA COOPERATIVA ESTATAL Y EL EXPERIMENTO FINANCIERO}

Bodegas Giol ha sido, sin dudas, el instrumento de intervención estatal más drástico y controvertido en 150 años de historia de la agroindustria vitivinícola argentina, esto es desde su transformación de actividad artesanal a industrial a fines del siglo xIx. No obstante, las medidas impulsadas 
por las dirigencias políticas y empresariales para afrontar y superar las crisis de principios del siglo $\mathrm{xx}$ fueron diversas, e incluyeron: la creación de entidades reguladoras para reducir los excedentes vínicos (Olguín, 2012; Ospital y Cerdá, 2016) ${ }^{3}$ la eliminación de aranceles a la exportación de vinos; el estímulo a la formación de cooperativas (Mateu, 2002); la construcción de bodegas regionales, depósitos de corte de vinos y destilerías; y el crecimiento de las exportaciones. Los mecanismos de acción se profundizaron luego del dramático declive que sufrió la agroindustria poco antes del estallido de la Gran Depresión y hasta fines de la década de 1930, en un contexto de profesionalización de la administración pública y creación de instituciones especializadas en economía, finanzas y estadística. Así, se fundó la Junta Nacional Reguladora de Vinos (1934-1943), que efectivamente eliminó una gran cantidad de cepas, uvas y vinos y, con ello, provocó una fuerte reducción de la oferta de vinos y el alza transitoria de los precios (Olguín, 2012, p. 94). Se unificaron los impuestos nacionales y provinciales al consumo - un antiguo reclamo de las asociaciones empresariales vitivinícolas (Ospital, 2013, p. 32) - y se puso en marcha el Instituto Movilizador de Inversiones Bancarias en 1935, con el propósito de administrar empresas con una comprometida situación patrimonial (entre ellas, la propia Bodegas Giol). También se sancionó una ley general de vinos en 1938 (núm. 12.372), que estableció controles sobre la procedencia y la calidad del producto y creó la Dirección General de Vitivinicultura como organismo contralor. En el ámbito provincial, se organizó la sección antifiloxérica y de patología vitícola en 1936.

A mediados de la década de 1940, la oferta y la demanda de vinos recuperaron su sendero de crecimiento gracias a la reactivación económica y al aumento del salario real de los trabajadores. Los menguados viñedos resultaron insuficientes para satisfacer el mayor consumo, por lo cual la política vitivinícola dio un giro en favor de la expansión de las plantaciones de vid y una menor exigencia de calidad enológica 4 Por otra parte, la legislación provincial se preocupó no sólo por los problemas de abastecimiento, sino también por mejorar las condiciones laborales y de producción de los sectores más vulnerables de la cadena productiva: estableció el estatuto de contratistas de viñas y frutales en 1945, reglamentó su trabajo y fijó sus remuneraciones. Asimismo, el poder ejecutivo provincial creó el Instituto de Investigación de la Vid y el Vino y el Departamento de Cooperativas (decreto 5411/1953) e impulsó la compra de Bodegas Giol en 1954 para contribuir a la integración vertical de los viñateros sin bodega y la regulación de precios (Mateu, 2014; Mateu y Olguín, 2006; Olguín, 2013b).

La firma fue protagonista de la historia económica y política de Mendoza desde los inicios del siglo xx. Tenía su antecedente en la firma La Colina de Oro, fundada en 1898 por dos inmigrantes, Juan Giol, procedente de Vigonovo di Fontanafredda (Udine, Italia) y su concuño, Bautista Gargantini, originario del Canton Ticino (Suiza). Luego de un veloz proceso de ampliación de la estructura productiva y comercial en un contexto de fuerte crecimiento de la economía argentina, se consolidó como una firma líder -disputando esta posición sólo con la bodega Tomba-: en 1910 su producción superaba los 300000 hectolitros de vino y la marca Toro la distinguía en todo el país. En 1911, la sociedad se disolvió (Gargantini regresó a Suiza) y Juan Giol constituyó

\footnotetext{
${ }^{3}$ Otras entidades que intentaron reducir los excedentes vínicos: la Comisión de Defensa y Fomento Industrial y Comercial (1914), la Compañía Vitivinícola de Mendoza (1916), la Comisión Autónoma de Defensa Vitivinícola (¿1933?).

${ }^{4}$ En consonancia, se dispuso la disolución de la Junta Reguladora de Vinos y el levantamiento de las limitaciones a la liberación de vinos al consumo en 1943 y de los controles al comercio en 1944. A su vez, la Secretaría de Industria y Comercio estableció precios máximos al vino de mesa a partir de 1948 para enfrentar las presiones inflacionarias. De igual modo, se establecieron cuotas provisorias de expendio de vinos a las bodegas en 1950 y un régimen de ordenamiento para la distribución de comercialización de vinos de Mendoza y San Juan (1952-1954).
} 
la Sociedad Anónima Bodegas y Viñedos Giol, junto con el Banco Español del Río de la Plata y otros inversores minoritarios, entre los que se encontraban comerciantes de vino; Giol, además, ejerció como administrador general. La empresa se destacó también en innovación tecnológica, a tal punto que en 1914 inauguró el vinoducto aéreo más grande del mundo, que transportaba el vino producido en la bodega La Colina de Oro a la bodega El Progreso (ambas localizadas en Maipú, Mendoza); en esta última era fraccionado y despachado por ferrocarril a los principales centros de consumo, especialmente a Buenos Aires, Santa Fe y Córdoba (Olguín, 2010). Un año más tarde, mientras la agroindustria se sumergía en una profunda crisis e Italia ingresaba en la primera guerra mundial, Juan Giol regresó a Italia con su familia (quedando en Argentina su hijo mayor, Humberto), pero decidió conservar sus acciones hasta 1925. Allí puso en marcha la Azienda Agricola Giovanni Giol, la cual fue capitalizada con flujos de fondos girados periódicamente desde Argentina (Olguín, 2016). Por otra parte, el financiamiento del Banco Español contribuyó a ampliar la estructura comercial instalando plantas de fraccionamiento de vinos en los principales mercados consumidores del interior argentino, y a sortear la crisis de la década de 1930. Pero la difícil coyuntura de principios de la década de 1950, las restricciones a la comercialización del vino instauradas en la década peronista y los controles a la oferta de crédito bancario agravaron la situación financiera de Bodegas Giol, llevando a las autoridades de la empresa a ofrecer su venta al candidato electo por el Partido Justicialista: ${ }^{5}$ Carlos Evans, en 1952 (Olguín, 2013b).

La pieza clave sobre la que los funcionaros ligados al círculo íntimo del poder ejecutivo estructurarían el programa económico se incorporó al estado provincial en el tramo final de la segunda presidencia de Juan D. Perón (1952-1955) ${ }^{6}$ Frente al cambio de rumbo que había adoptado la política económica nacional durante la crisis de 1952 y el pedido de austeridad realizado por Perón, algunos funcionarios del Ministerio de Hacienda y de Economía de la provincia de Mendoza pensaron que la firma podría colaborar en el cumplimiento de los objetivos específicos del segundo plan quinquenal. El poder ejecutivo adquiría "por fin un instrumento para la sana diversificación de sus varios productos que aleje a Mendoza de sus encrucijadas ante cada cosecha deficiente o superabundante" (Evans, 1954, pp. 35-36) y para obtener recursos para financiar un cuantioso plan de obras públicas (Caplán, 1957, pp. 33-34).

Las negociaciones entre el gobierno y el Banco se realizaron en un contexto de exceso de oferta de vinos, ampliación de la brecha entre elaboración y despachos y elevada inestabilidad. La década de 1950 marcó el fin del ciclo expansivo que había seguido a la recuperación de la crisis económica del decenio de 1930. La liquidación de la Junta Nacional Reguladora de Vinos en 1943 y el aumento del consumo per cápita venían estimulando la implantación de vides y, con ella, la producción de uvas y vinos. Pero la crisis económica nacional de 1951-1952 provocó un fuerte descenso del ingreso disponible, y con él en el consumo de vinos, empujando al alza de precios. Por el contrario, en 1954 y 1957, las caídas en la producción fueron pronunciadas, por efecto de los accidentes climáticos y las plagas de la vid, respectivamente. De hecho, la menor cantidad de

${ }^{5}$ El Partido Justicialista, continuador del Peronista, fue fundado por Juan D. Perón en 1947 bajo el emblema de la justicia social.

${ }^{6}$ En ese entonces, Bodegas Giol era una de las firmas vitivinícolas más grandes del país. De acuerdo con el informe de tasación, su activo estaba formado por casi una veintena de fincas con 1608 hectáreas de viña y 2596 hectáreas con otros cultivos y sin cultivar, las bodegas La Colina, El Progreso y La Florida, y sucursales en Palermo, Junín (Buenos Aires), Mar del Plata, Rosario, Córdoba, Barranqueras (Chaco) y Tucumán, además de 197 tanques de ferrocarril montados en 101 vagones y 80 automotores. A su vez, empleaba a 2337 personas, disponía de una capacidad de elaboración en vasija de madera y roble de 800000 hectolitros (que representaba $4.3 \%$ del total provincial) y comercializaba sus vinos en 18000 almacenes de todo el país (Olguín, 2013b, p. 242). 


\section{GRÁFICA 1. ELABORACIÓN Y DESPACHOS DE VINO EN MENDOZA, 1944-1966}

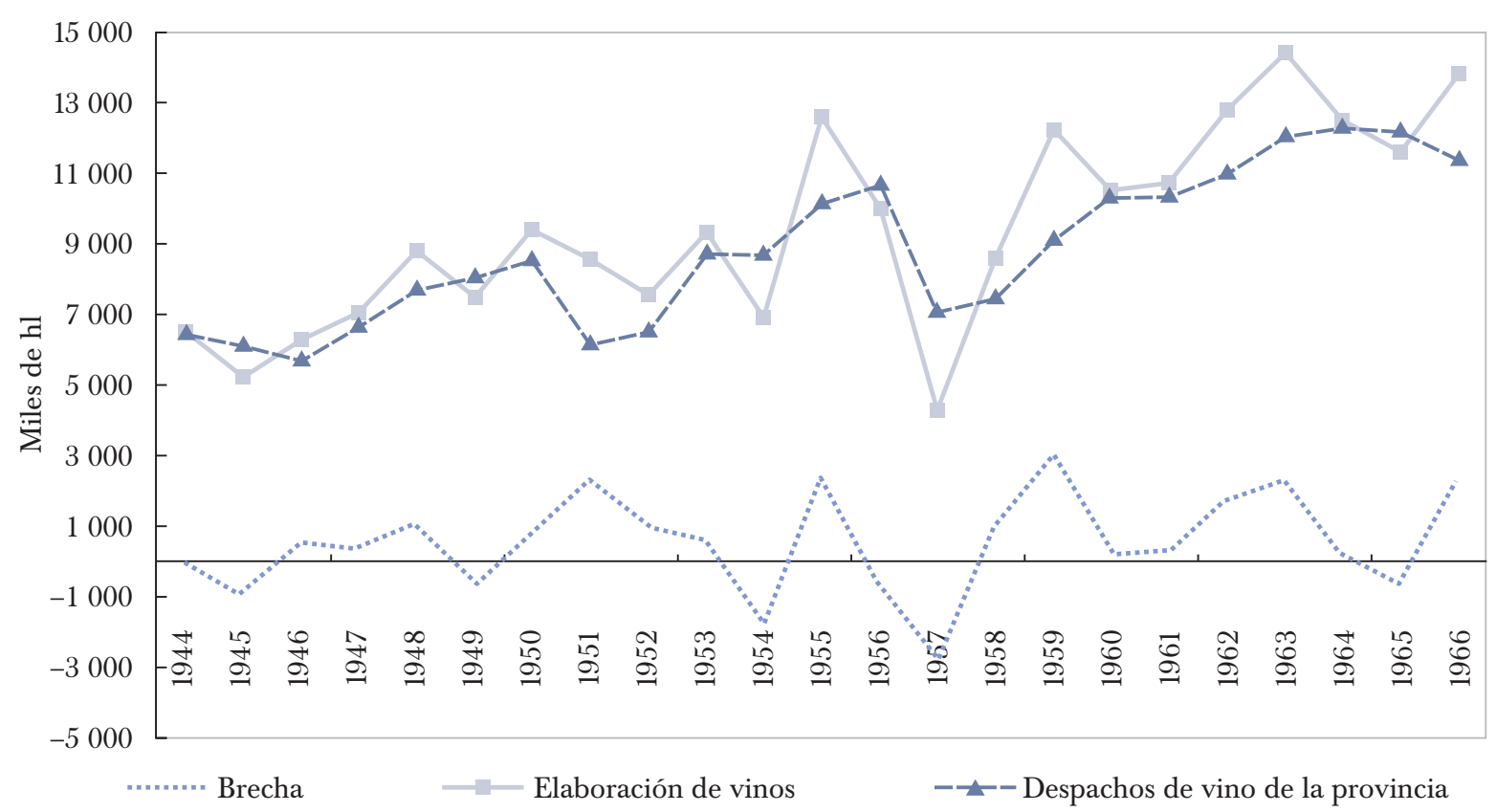

Fuentes: elaboración propia con base en Gobierno de Mendoza (1952, pp. 58-59), Instituto de Investigaciones Económicas y Tecnológicas (1962, s. p.) e Instituto Nacional de Vitivinicultura (1987, pp. 5 y 9 ).

vino disponible provocó un fuerte aumento en los precios, aun cuando en 1957 y 1958 los niveles de consumo fueron bajos debido a la mala propaganda que significó la muerte de ocho personas por la ingesta de vinos adulterados (véanse gráficas 1 y 2).

En esta coyuntura, el proyecto pensado para Bodegas Giol estableció una dimensión económica y otra financiera. En cuanto a la primera, la estructura organizacional de la firma sería utilizada como instrumento de diversificación productiva y de integración de la cadena de valor de las principales agroindustrias de Mendoza: la vitivinicultura, la fruticultura y la horticultura.7 ${ }^{7}$ Con ello, se buscaba que los pequeños y medianos productores agrícolas pudieran industrializar sus productos en los establecimientos de Bodegas Giol y, junto con los bodegueros trasladistas, distribuirlo en sus vagones de ferrocarril y en sus camiones-tanque hacia las plantas de fraccionamiento y sucursales ubicadas en las principales ciudades del país. De este modo, el empresario podría obtener un producto con mayor valor agregado y menos perecedero que le permitiría elegir con mayor flexibilidad el momento de venta -sin el apremio de la pérdida de calidad de la fruta o de la verdura en fresco- y llegar directamente al consumidor, eliminando a los intermediarios comerciales que a menudo disfrutaban de un mayor poder económico para negociar los precios.

Además, la ley que autorizó la compra de las acciones de Bodegas Giol preveía el traspaso de $49 \%$ del total de las acciones ordinarias y del total de las preferidas a cooperativas, pequeños productores y trabajadores de la firma, lo cual implicaba que los propios agentes económicos se

\footnotetext{
${ }^{7}$ Los lineamientos generales de la función de Bodegas Giol en la economía provincial fueron expuestos por el ministro de Economía, Mario Ceresa, durante el tradicional banquete de las fuerzas vivas ofrecido por las entidades empresariales al finalizar la cosecha, el 12 de marzo de 1955. Los Andes, 13 de marzo de 1955.
} 


\section{GRÁFICA 2. PRECIOS REALES DE LA UVA EN CEPA Y DEL VINO DE TRASLADO EN} MENDOZA, 1956-1966

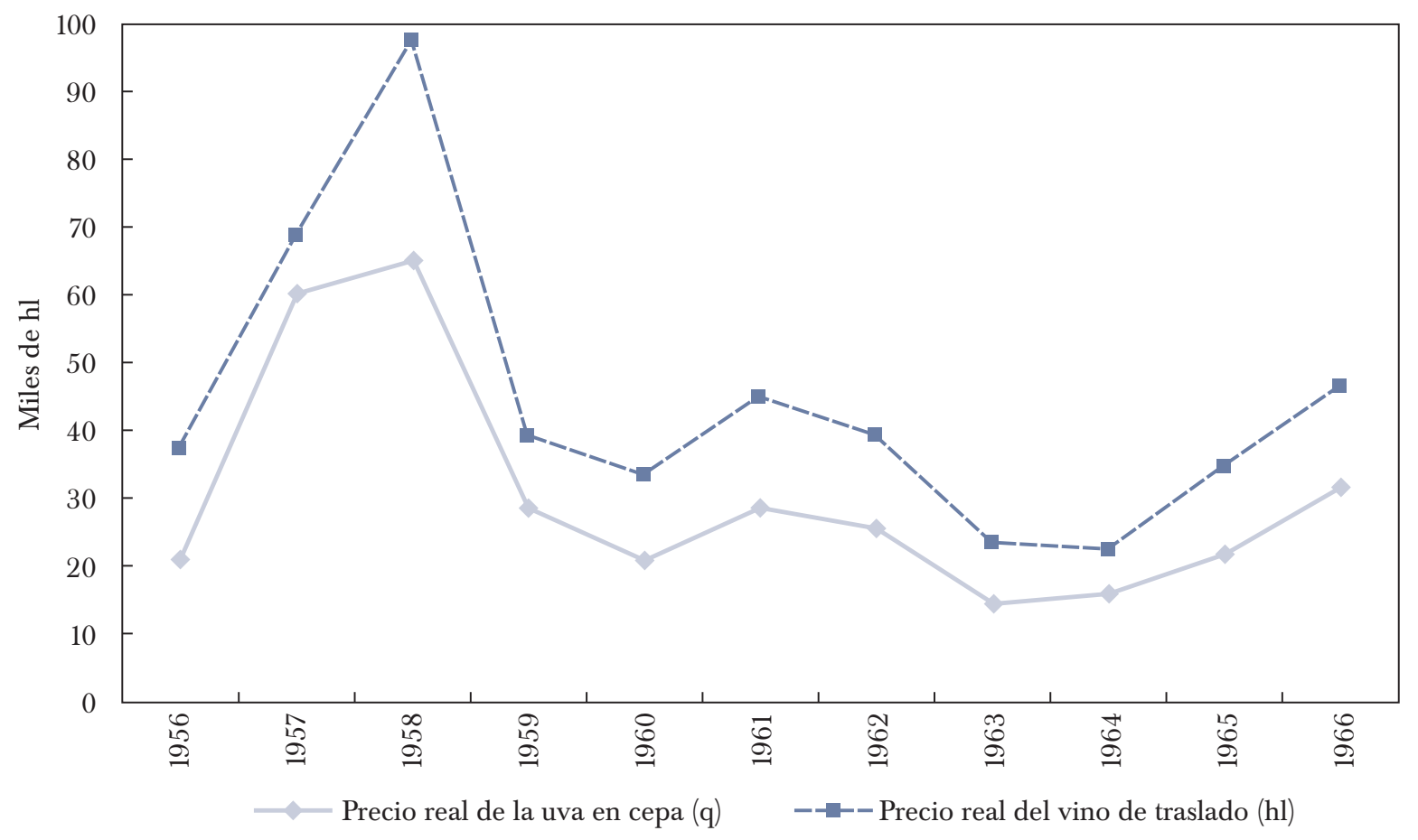

Fuentes: elaboración propia con base en Gobierno de Mendoza (1967, p. 37) y ([1969], p. 36), Birentzwaig (1982, p. 254) e Instituto Nacional de Estadísticas y Censos (2015).

autogestionarían en sociedad con el Estado. En definitiva, como había señalado el senador Luis Vinassa en el debate legislativo del proyecto de ley, se trataba de convertir a la "Sociedad Anónima Giol en una cooperativa al servicio del pueblo y de los hombres trabajadores de Mendoza" 8 es decir, en una cooperativa estatal. Esta concepción, que entendía a las cooperativas como la forma de organización económica que permitiría enfrentar la concentración en los eslabones de la cadena vitivinícola, mejorar la distribución del ingreso y atenuar la inestabilidad de los ciclos económicos en los mercados de base agraria, tenía larga data en las discusiones de política vitivinícola desarrolladas entre expertos y dirigentes políticos y empresariales desde los inicios del siglo xx. Sin embargo, resultaron infructuosos los intentos realizados por extender este tipo de organización basada en lazos de solidaridad por parte de las distintas gestiones gubernamentales que se habían sucedido desde 1918.

Fue la tercera gestión peronista, a cargo de Carlos Evans, la que realizó la mayor apuesta, tomando el control de Bodegas Giol bajo el amparo de un marco institucional que había avanzado en la profundización de la intervención del Estado en la economía y en la protección de los pequeños productores a través de la promoción del cooperativismo, que constituía una de sus principales preocupaciones. En efecto, si bien un grupo de técnicos de la década de 1930 había dejado un

\footnotetext{
${ }^{8}$ Luis Vinassa [29 y 30 de abril de 1954]. Diario de Sesiones (periodo extraordinario, 1953-1954, p. 1767). Mendoza: Imprenta Oficial.
} 
importante legado en relación con instrumentos regulatorios, "la creación de un marco institucional nuevo fue, sin duda, resultado del peronismo" (Cortés, 2003, p. 212). En efecto, en 1950 el país poseía las instituciones que los partidarios de la industrialización habían demando durante décadas y que se estaban generalizando en América Latina (Belini, 2009, p. 21). Asimismo, la Constitución de la provincia de Mendoza sancionada en 1949 (arts. 54 y 62), a diferencia de la Constitución Nacional, instaba expresamente al fomento del cooperativismo, tanto en relación con la política agraria y la vitivinícola, en particular, como con el crédito oficial. El segundo plan quinquenal, por su parte, elaborado para Mendoza en consonancia con el del gobierno nacional, otorgaba a las entidades organizadas bajo estos principios un lugar central en la economía. Evans otorgó a las cooperativas una función clave en su programa de gobierno porque entendía que conjugaban los valores del colaboracionismo y de la justicia social 99 Igual importancia les asignó a las formas activas del cooperativismo en los discursos que pronunció para difundir el segundo plan quinquenal 10

Este fervor por el cooperativismo fue compartido por el ingeniero agrónomo Mario Ceresa, ministro de Economía de la provincia (1952-1955), funcionario de carrera en la administración pública y que más tarde incursionó en el negocio vitivinícola como socio de la Bodega Ceresa Hnos. Ya en sus años de universidad había analizado las ventajas de cooperación vitivinícola para los viñateros sin bodega y los pequeños bodegueros, considerándolo el instrumento adecuado para modificar no sólo la estructura industrial, sino la comercial y así "lograr la estabilización definitiva del mercado de vinos" (Ceresa, 1943, pp. 222-224) ${ }^{11}$ La insistencia en las distorsiones que se producían en la cadena de comercialización fue uno de los puntos centrales de su perspectiva sobre las dificultades que frenaban el desarrollo de la vitivinicultura mendocina. El cooperativismo ingresaba en este esquema de pensamiento como un resorte de extraordinario valor. El futuro de la industria dependía entonces de la armonización entre la actividad privada y la estatal (Ceresa, 21 de abril de 1953). Para ello, el Estado debía fomentar estas asociaciones, en otros instrumentos, con el crédito agrícola. En esta dirección, durante su gestión como ministro se crearon el Instituto de Seguro Agrícola, el Instituto de la Vid y el Vino y la Dirección de Cooperativas, desde donde habría gestionado la formación de cooperativas. Si bien algunos autores sostienen que superaron el centenar en dos años (1953-1955) (Micale, 1999, p. 96), el propio Evans declaró en 1955 que en Mendoza existían 30 cooperativas vitivinícolas que reunían 761 viñateros. ${ }^{12}$ Más aún, de acuerdo con los registros de la Dirección General de Industrias, de los 830 establecimientos industriales que elaboraron vino en 1955, sólo siete correspondían a cooperativas, las cuales fueron responsables de $1.4 \%$ de la elaboración total ${ }^{13}$ De modo que, en ese periodo, la importancia del cooperativismo en la vitivinicultura mendocina fue más cualitativa que cuantitativa, al contrario de lo que sostienen algunos autores (Cerdá, 2018, p. 42). Su desarrollo fue tardío en relación con Francia o Italia, y contemporáneo con el de España. La existencia de un marco legislativo específico y la asistencia financiera por parte del Estado franquista -que han sido individualizados como algunos de los

\footnotetext{
${ }^{9}$ Carlos Evans (1954). Diario de Sesiones (periodo 1952-1953, p. 32). Mendoza: Imprenta Oficial.

${ }^{10}$ Mensaje a la Legislatura (4 de junio de 1953), en Gobierno de Mendoza (1953, p. 1).

${ }^{11}$ Trabajo final para obtener el título de ingeniero agrónomo por la Universidad Nacional de La Plata publicado en Revista de la Facultad de Agronomía. Luego escribiría numerosos trabajos vinculados a los aspectos técnicos y económicos de la vitivinicultura y artículos de opinión en la prensa mendocina.

${ }^{12}$ Evans (1955, p. xx).

${ }^{13}$ No se han podido identificar en los registros 45 bodegas de Guaymallén, por lo cual estos números podrían ser ligeramente mayores.
} 
principales factores de desarrollo del cooperativismo vitivinícola en este último país (MedinaAlbaladejo, 2016, p. 49)-, no tuvieron la misma fuerza en Argentina; en cambio, como se verá más adelante, allí el soporte público se puso a disposición de empresas estatales (Bodegas Giol) o con participación estatal (CAvic).

Por otra parte, en su dimensión financiera, el plan del gobierno para la firma analizada, luego de sanear sus finanzas y consolidar su estructura económica mediante un proceso de racionalización, era convertirla en una sociedad madre de otras firmas subsidiarias de tipo semipúblico (o mixtas, es decir, con aporte de capital público y privado). Estas empresas, organizadas bajo los principios de la autofinanciación (según la cual cada empresa debía generar ingresos para cubrir por lo menos sus propias necesidades y no gravitar en el presupuesto del Estado) y del accionariado obrero, proporcionarían mayor flexibilidad administrativa y un acceso más fácil a las fuentes de capital. De ese modo, se pensaba utilizar el crédito, el capital y la organización de Bodegas Giol para poner en marcha otros proyectos agrícolas, comerciales, industriales y sociales, que en algunos casos no tenían ninguna relación con la agroindustria $\sqrt{14}$ En el fondo, se pretendía utilizar la firma para crear una fuente de recursos adicional a la tributaria a fin de desarrollar un ambicioso plan de obras públicas. Se trataba, en suma, de un experimento financiero -como fue denominado por el mismo ministro de Hacienda, Benedicto Caplán- que daría vida a una multiplicidad de sociedades subsidiarias que "constituían la médula de todo el plan económico" (Caplán, 1957, pp. 73-74, 84 y 87-102). La empresa contribuiría así a financiar la diversificación de la estructura económica de Mendoza. Este objetivo resultaba consistente con los hacedores de la política pública peronista que sostenían que la diversificación de la estructura industrial atenuaría el impacto local de los ciclos de crecimiento y recesión del mercado internacional; creían que una economía más diversificada y menos centrada en el mercado externo permitiría una mayor estabilidad del cuerpo social y una mejor redistribución de la riqueza (Belini, 2009, p. 10).

El programa de gobierno para el periodo 1952-1958, cuya elaboración Evans había encargado a Caplán, entonces secretario de Finanzas, y a José J. Bonamico, secretario técnico de la Gobernación, se apoyaba en la idea de que el desarrollo económico de Mendoza debía fundarse en grandes planes de obras públicas por su efecto multiplicador en la economía. Este propósito era difícilmente realizable en el marco del plan económico anunciado por Perón en 1952, a través de un mensaje radiofónico, que establecía como una de sus prioridades la reducción del gasto público y "la racionalización de las obras públicas a los límites absolutamente indispensables". De hecho, los gastos de capital que habían constituido uno de los pilares del modelo de desarrollo peronista y se habían multiplicado por 3.5 a precios constantes entre 1940-1944 y 1945-1949, cayeron $30 \%$ durante el quinquenio 1950-1954 (Gerchunoff y Antúnez, 2002, p. 174). A su vez, la distribución de estas obras estaba en el centro de las presiones políticas y sindicales. El mismo Caplán (1957, p. 34) afirmó que "los demás ministros, los legisladores, los altos funcionarios de la Administración, así como los dirigentes gremiales y políticos que sostenían al Gobierno, haciéndose eco de intensas necesidades populares, exigían la aprobación de un plan de obras de envergadura”. En el fondo de

\footnotetext{
${ }^{14}$ Los principales serían la construcción de viviendas, la preparación de tierras para agricultura (motocultura), la formación de un mercado regional frutihortícola con un frigorífico anexo, la creación de una empresa de artes gráficas para prestar el servicio de la publicidad de la empresa y de una organización mutualista y la construcción de obras de regadío.
} 
la cuestión también estaba la impronta que tenían los gobiernos peronistas en Mendoza, los cuales habrían respondido a las demandas de los distintos sectores a través de este mecanismo y no tanto del nombramiento de empleados públicos ${ }^{15}$

El interés por satisfacer estas expectativas llevó a concebir un plan de enormes proporciones que requería una inversión de 1500 millones de pesos moneda nacional (en adelante pesos) en seis años - 250000000 de pesos por año-, cuando lo máximo que se había invertido en obras públicas en Mendoza en un año había sido 30000000 de pesos ${ }^{16}$ Estos valores resultaban aún más desmesurados teniendo en cuenta la delicada situación de las finanzas provinciales. El propio gobernador, admitió que la tarea más difícil era la del Ministerio de Hacienda. ${ }^{17}$ Las arcas del Estado sólo disponían de fondos para cubrir el presupuesto ordinario, es decir, los gastos de funcionamiento del aparato estatal que se cancelaban con los impuestos recaudados, y ni siquiera quedaba un remanente para cubrir una deuda por obras en ejecución, contraída por la gestión anterior. Asimismo, la provincia tenía un acceso limitado al crédito para hacer frente a ese compromiso y poner en marcha un presupuesto extraordinario para construir obras públicas, lo cual estaba vinculado a la política del Banco Central de sostener las cotizaciones de los títulos, principalmente, los de la nación. 18

La creación de empresas semipúblicas o públicas que se financiarían por sí solas resultaba para las mentes inquietas de estos funcionarios la solución apropiada para concretar una inversión en obras de proporciones colosales para la época. La utilización del principio empresario en las finanzas públicas para alcanzar estos fines fue una de las principales innovaciones introducidas por el tercer gobierno peronista en Mendoza, en términos de política económico-financiera. En efecto, la política nacional en relación con la creación de empresas industriales durante la década peronista estuvo fuertemente orientada a desarrollar nuevas industrias cuyos grandes requerimientos de capital alejaban a los inversores privados (como la siderúrgica o las automotrices), mantener en funcionamiento empresas con dificultades cuyas actividades se consideraban estratégicas (como las firmas farmacéuticas, químicas, metalúrgicas y eléctricas agrupadas en la Dirección Nacional de Industrias del Estado) o a dirigir empresas en las que había obtenido el control luego de pleitos económicos y políticos (empresas del grupo Bemberg) (Belini y Rougier, 2008, p. 30). Ninguno de estos propósitos se asimilaba a los de Evans, Caplán y Bonamico.

\footnotetext{
${ }^{15}$ Véase declaración de Ignacio González, ministro de Economía del segundo gobierno peronista, en Junta de Estudios Históricos de Mendoza (1996, p. 184).

${ }^{16}$ Sin embargo, se decidió incluir en el segundo plan quinquenal una cifra de 800000000 de pesos que todavía resultaba superior a las de toda la historia de Mendoza y a las pretensiones de las demás provincias, si se tiene en cuenta el monto total en relación con la población (Caplán, 1957, p. 30). En 1954, la cotización del dólar estadunidense en pesos - promedio anual- en el mercado libre era de 13.97 (Olarra, 1968, p. 184).

${ }^{17}$ Carlos Evans (1954). Diario de Sesiones (periodo 1952-1953, p. 28). Mendoza: Imprenta Oficial.

${ }^{18}$ La máxima autoridad bancaria había suspendido la inscripción de títulos provinciales en la Bolsa de Comercio. Así, entre 1947 y 1955 la Comisión de Valores del Banco Central no autorizó ninguna inscripción de títulos provinciales (excepto tres partidas de 5000000 de pesos cada una durante el mandato de Caplán). El gobierno provincial sólo disponía de préstamos federales, cuyos fondos provenían del sistema de previsión social distribuidos por la nación. A Mendoza le correspondieron 150000000 de pesos para el periodo 1953-1958, en tanto que las obras contratadas por el gobierno anterior sumaban 270000000 de pesos (Caplán, 1957, pp. 27 y 31-33).
} 
El mentor de estas ideas fue Benedicto Caplán 19 Formado en ciencias políticas, fue un hombre apasionado por la economía pública y un entusiasta de las potencialidades de los instrumentos de política económica para modificar las condiciones de vida de la población (Caplán, 1955, 1956). Su admiración por las ideas keynesianas y su convicción sobre la necesidad de contar con la "iniciativa y organización adecuada para combinar y aprovechar los elementos y factores disponibles" lo acercaron al ideario peronista, llegando a ser rápidamente uno de sus funcionarios más destacados a nivel provincial. Habría accedido al cargo de secretario de Finanzas por ofrecimiento de Carlos Evans, a pesar de ser un hombre desconocido en el medio local y ajeno al partido peronista (Caplán, 1957, pp. 9 y 25), lo cual aparentemente no constituyó un obstáculo para el jefe del poder ejecutivo que, en sus designaciones, habría privilegiado las capacidades técnicas a los vínculos políticos y personales, como muestra la composición de su gabinete y recuerdan sus colaboradores más cercanos (Cuadra, 1998, pp. 15-19).

Bodegas Giol era el instrumento ideal para echar a andar la rueda de la creación de empresas semipúblicas, al mismo tiempo que contribuiría a resolver los problemas de una economía demasiado dependiente de una industria de base agraria. "Además de las posibilidades financieras, que eran primordiales, el Estado tenía la posibilidad de crear pacíficamente el mercado del vino y entrar en posesión de una palanca comercial poderosa y susceptible de expansión, mediante la cual podría no sólo regular la industria vitivinícola, sino obtener mercados para numerosas otras mercancías de producción factible en la Provincia” (Caplán, 1957, pp. 73-74). Estas ideas también fueron expresadas por Emilio Fluixá, diputado peronista (1952-1955) y presidente de la Cámara durante el tratamiento de la ley 2.301, a un periódico local 23 años más tarde de realizada la operación: "La razón fundamental -para comprar- es que la Provincia, cuando asume el Dr. Evans, tenía una deuda que, con los ingresos normales, hubiéramos demorado 9 años en cancelar. Esto anulaba toda posibilidad de realizar obras públicas. Entonces surgió entre la gente de gobierno la idea de encontrar otros recursos, en otras actividades reproductoras de bienes, que pudieran ir en apoyo del presupuesto. 20

De esta manera, los dos proyectos, la cooperativa estatal y el experimento financiero, resultaban complementarios, aunque el segundo prevalecería sobre el primero; en efecto, una vez adquirida la firma por el estado provincial, el presidente del directorio fue Caplán y no Ceresa. Del proyecto financiero no sólo dependía el cumplimiento del plan de obras públicas establecido en el segundo plan quinquenal, sino también la posibilidad de responder a las demandas de las bases para mantener la armonía en el seno del peronismo local, reforzar el liderazgo de Evans y resguardar así la estabilidad institucional.

El proceso de saneamiento económico y financiero que permitiría poner en marcha los planes propuestos se inició inmediatamente después de que Caplán asumiera como presidente del directorio de Bodegas Giol, el 4 de mayo de 1954. Sin embargo, el golpe de Estado del 16 de septiembre de 1955 que precipitó la caída de Perón impidió su desarrollo. El proyecto pensado para la firma fue interrumpido por las intervenciones federales de la llamada Revolución Libertadora, que la colocaron al borde de la parálisis operativa. Esa coyuntura resultó propicia para abrir un debate en torno a la forma jurídica más apropiada para la empresa vitivinícola a fin de que

\footnotetext{
${ }^{19}$ Benedicto Caplán había nacido en Entre Ríos. Se graduó de doctor en ciencias políticas en 1936 y publicó una docena de trabajos de investigación entre 1937 y 1941 en la Universidad Nacional del Litoral. Ante la dificultad para ejercer su profesión, se había dedicado al comercio. Llegó a Mendoza en 1946, contratado como profesor por la Universidad Nacional de Cuyo para dictar el Curso de Especialización en Finanzas (Caplán, 1957, pp. 26-27).

${ }^{20}$ Mendoza, 23 de diciembre de 1980.
} 
asumiera una intervención activa en el mercado vitivinícola. Las principales alternativas giraron en torno a una empresa privada, una cooperativa o una sociedad de economía mixta. Si bien los sectores políticos y empresariales se inclinaron en favor de esta última, la conflictividad política demoró la definición sobre la cuestión.

Con la caída del peronismo se inició una etapa de reacomodo de la función del Estado en la actividad económica. La Secretaría de Comercio suprimió las limitaciones para elaboración de vinos en 1955, creó una comisión asesora honoraria del vino en 1956, ordenó a las bodegas la venta de vinos en Mendoza y San Juan en 1957 (ante la reducida cosecha después de una plaga que atacó los viñedos) y estableció sanciones en 1958 para la adulteración, que estimuló esta coyuntura y que provocó la muerte de varias personas. Esta última situación y la preocupación por la calidad, junto con la llegada al poder de los gobiernos desarrollistas, condujeron a la sanción de una nueva ley de vinos que fundó en 1959 el Instituto Nacional de Vitivinicultura, como organismo de promoción y contralor técnico de la producción y del comercio vitivinícola. Entre otras disposiciones, dicha entidad estableció el fraccionamiento de vinos en las zonas de producción en 1963, aunque la medida no prosperó al ser duramente resistida por los intermediarios comerciales, y restringió el establecimiento de plantas de corte de vinos (que, a menudo, eran utilizadas para estirar el producto). Sin embargo, en los años siguientes, las políticas públicas nacionales contribuirían al aumento de la oferta de uvas de alto rendimiento y de baja calidad enológica mediante la promoción de incorporación de zonas áridas a la producción ${ }^{21}$ sin advertir que el consumo per cápita estaba a punto de alcanzar su máximo histórico e iniciar un largo proceso de declinación.

Por su parte, en la esfera provincial, se formó una comisión asesora sobre la forma jurídica definitiva para Bodegas Giol, se estableció el seguro agrícola obligatorio en 1955 y se prohibió transitoriamente la venta de vinos en 1957, a causa de los sucesos desencadenados por la falsificación. Asimismo, se prorrogaron los contratos de los contratistas de viña en 1958, se establecieron modificaciones al seguro agrícola y se creó el Instituto Financiero Agrario en 1962. También se establecieron medidas para la cosecha vitícola y se propició un tipo de vino de calidad certificada con precios obligatorios. Un hecho clave fue la transformación de la sociedad anónima Bodegas Giol en empresa estatal en 1964, asignándole por ley una función reguladora, la cual fue acompañada por la fijación de precios máximos al vino de traslado y precios mínimos a la uva en cepa en Mendoza en el bienio 1964-1965.

\footnotetext{
${ }^{21}$ Influyeron en este proceso la modificación a la ley nacional 11.682 de impuesto a los réditos y ley nacional 16.833 en 1966.
} 


\section{EL PROYECTO DE LA ELABORACIÓN DE VINOS PARA TERCEROS Y LA REGULACIÓN DE PRECIOS}

La discusión sobre la forma jurídica más apropiada para Bodegas Giol cobró fuerza cuando el dirigente del Partido Demócrata ${ }^{22}$ Francisco Gabrielli ${ }^{23}$ asumió por segunda vez el cargo de gobernador de Mendoza (1963-1966). Por una parte, la orientación de la política económica del gobierno del presidente Arturo Illia ofreció un escenario más favorable para la agroindustria vitivinícola, y para la reactivación de dicha empresa en particular, en tanto promovía el desarrollo del mercado interno, la distribución del ingreso y la protección del capital nacional bajo el control y la planificación económica del Estado. Asimismo, la reputación de los demócratas en la búsqueda de la eficiencia administrativa y en el orden en las finanzas públicas, junto con la debilidad del sindicalismo vitivinícola, pudieron haber contribuido a que los nuevos planes para Bodegas Giol no fueran percibidos como necesariamente riesgosos para el presupuesto público. Sobre todo, teniendo en cuenta que, a nivel nacional, el cumplimiento de la promesa electoral de dar marcha atrás con las privatizaciones iniciadas en época de la presidencia de Arturo Frondizi (1958-1962) y los incrementos del plantel de personal, los salarios y el gasto en las sociedades con control estatal, ampliaron el tamaño del Estado. En efecto, creció el déficit en los organismos descentralizados y en las empresas estatales -un ejemplo emblemático fue el de los ferrocarriles que en 1965 pasaron a ser responsables de $20 \%$ de los gastos del gobierno centra-l (Mallon y Sourrouille, 1976, p. 36). La pretensión de incrementar las exportaciones industriales, objetivo que fue incluido en el plan nacional de desarrollo elaborado por el Consejo Nacional de Desarrollo (CONADE), que fue terminado en 1965 e iba a ponerse en práctica cuando Illia fue derrocado en 1966 (Sikkink, 2009, pp. 129-130), se encontraba también entre los propósitos de la empresa.

El cumplimiento de una función social por parte del empresariado fue otra iniciativa propiciada por el gobierno nacional (Tcach y Rodríguez, 2006, pp. 91-92) que tuvo su correlato en Bodegas Giol. En este sentido, el presidente de la firma y dirigente del Partido Demócrata de Mendoza, Manilo Ardigò sostuvo que "en Giol se busca armonizar los intereses legítimos como empresa y los de la economía general de la Provincia. Para una empresa corriente, no le resultaría de interés adquirir uvas en pequeñas partidas a numerosos compradores. En el sur, citando un ejemplo, hay más de 1000 viñateros anotados con cantidades pequeñas de uva que entregará a Giol, que en esa forma cumple una evidente función social". ${ }^{24}$ Otro ejemplo de ello fue el operativo que puso en marcha la firma para asistir a los pequeños productores afectados por las heladas del 28 y 29 de marzo de 1964. La organización empresarial funcionó a tiempo completo para recibir las uvas dañadas -a pesar de la gran cantidad que ya había adquirido- y elaborar vino por

\footnotetext{
${ }^{22}$ El Partido Demócrata de Mendoza tuvo su origen en el antiguo Partido Conservador en 1917, que luego de un proceso de transformaciones y alianzas -Partido Autonomista (1920) y Partido Liberal (1921) - devino en el Partido Demócrata Nacional en 1931.

${ }^{23}$ Gabrielli contaba con una larga trayectoria en la función pública y un profundo conocimiento del negocio del vino. Nació en Mendoza en 1902. Era hijo de un bodeguero inmigrante. Se graduó de ingeniero en la Universidad de Buenos Aires. En la función pública actuó como ingeniero inspector de la Dirección General de Obras Públicas de Mendoza (1930), director presidente de la Dirección Provincial de Vialidad (1934-1941) y superintendente de la Dirección Provincial de Irrigación (1941 y 1946). Se inició en la actividad política en 1924 en las filas del Partido Liberal, antecedente del Partido Demócrata (Micale, 1999, p. 19).

${ }^{24}$ El Tiempo de Cuyo, 24 de febrero de 1964.
} 
cuenta de terceros. Esta medida se complementó con la ley de expropiación de vasija vinaria 25 que permitió a los productores disponer de más bodegas y acceder a créditos del Banco de la Nación para cosecha, transporte y elaboración de vinos, con garantía prendaria sobre el vino a elaborar 26

Para el equipo económico del gobierno de Gabrielli, la vitivinicultura tenía una gran importancia como fuente de riqueza y factor de desarrollo económico. En 1960, el valor de la producción de uvas representaba $67 \%$ del valor de la agricultura, y el de la producción de vinos $40 \%$ del valor de las industrias de base agraria y minera (Gobierno de Mendoza, 1969). ${ }^{27}$ El propio ministro de Economía, Joaquín González Villanueva, a cuatro meses de iniciada la gestión gubernamental, afirmó que "nadie puede ser indiferente a la prosperidad o a la ruina de la vitivinicultura, en cuanto de ella depende la vida económica de la Provincia y la de sus habitantes" 28 Sin embargo, resultaba prioritario avanzar también en el desarrollo de otras industrias a fin de lograr lo que él mismo definió como la fisonomía ideal de Mendoza. Se trataba de trabajar por una provincia "con una agricultura altamente evolucionada acentuándose cada vez más su necesaria diversificación y con una industrialización paralela a sus necesidades que deberá completarse con otras nuevas porque poseemos esas materias primas -mineras y potencial energético- que nos acerca a la economía mixta, que como sabéis constituye un factor sustantivo de estabilidad"29 De modo que el mandatario entendía el binomio vitivinicultura-petróleo de forma complementaria y no excluyente. Por ello, sostuvo que si bien la industrialización sobre la base de la explotación de las riquezas mineras debía ser estimulada "sin reservas [...], el desarrollo del país necesitaba robustecer y alentar la economía tradicional” 30

Estas expresiones resultaban críticas de las políticas del presidente Arturo Frondizi que negaron a Bodegas Giol una función activa en la industria vitivinícola. En efecto, a fines de la década de 1950, si bien las estrategias de intervención desplegadas por el gobierno de Ernesto Ueltschi (1958-1961) y por la primera y breve gestión de Gabrielli (1961-1962) habían sido bien recibidas por los sectores políticos, empresariales y trabajadores de Mendoza, no lograron despertar el mismo entusiasmo en el gobierno nacional. Así, a pesar de las mejoras percibidas en los precios de la uva y del vino de traslado y en la colocación de la producción de los viñateros sin bodega por parte de los actores locales, la reticencia de las autoridades nacionales a financiar industrias productoras de bienes finales destinados al mercado interno (más predispuestas, en cambio, a apoyar la expansión de las de base minera, ahorradoras o proveedoras de divisas), había puesto un límite a las expectativas generadas en torno al potencial de la empresa como entidad reguladora y promotora y habría contribuido a persuadir a ambos gobiernos de la necesidad de transferirla al sector privado y de transformarla en una sociedad de economía mixta, respectivamente.

La reactivación de Bodegas Giol formaba parte del plan de desarrollo vitivinícola trazado por el gobierno de Gabrielli, cuyos principales objetivos eran estabilizar los ciclos de la economía vitivinícola, promover la integración vertical, elaborar vinos de calidad e incrementar las exportaciones vínicas. La firma, en tanto ente regulador, utilizaría su estructura organizacional para reducir los

\footnotetext{
${ }^{25}$ Ley provincial 2.962. Boletín Oficial de la Provincia de Mendoza, 24 de febrero de 1964.

${ }^{26}$ Los Andes, 31 de marzo de 1964 y 2 de abril de 1964.

${ }^{27}$ Estimación realizada con base en Gobierno de Mendoza ([1969], pp. 31-32).

${ }^{28}$ Discurso pronunciado por el ministro con motivo de anunciar los precios que pagaría Bodegas Giol por las uvas de la cosecha 1964 (16 de febrero de 1964). Los Andes.

${ }^{29}$ Discursos de Francisco Gabrielli en los actos de proclamación y transmisión del mando (Gobierno de Mendoza, 1963, p. 16).

${ }^{30}$ Discursos de Francisco Gabrielli ... (Gobierno de Mendoza, 1963, pp. 15 y 19).
} 
excesos de oferta en los mercados de uvas y de vinos que deprimían los precios de este último, agravando las consecuencias de la inestabilidad inherente a los mercados de base agraria a causa de las heladas, el granizo y las plagas de la vid. En función de ello, elaboraría el vino de los viñateros sin bodega en establecimientos propios y alquilados, poniendo a su disposición un producto de mayor valor agregado y por lo tanto de mayor precio; asimismo, sostendría los precios de las uvas a través de la compra de grandes volúmenes 31

A fin de lograr los objetivos restantes, Bodegas Giol, en tanto ente promotor, facilitaría su estructura y su capacidad gerencial, no sólo para elaborar y almacenar grandes volúmenes de vinos, sino también para comercializarlos en los mercados nacional e internacional. Sin embargo, desde la perspectiva del gobierno, la empresa podía contribuir parcialmente a conseguir estas metas. Existían problemas de fondo, como las excesivas inversiones en viñas de uvas criollas, las existencias vínicas, la caída de los precios del vino frente al aumento del consumo y, sobre todo, la insuficiencia de crédito, que requerían de un abordaje específico. Por lo cual, tendrían que intervenir además otros organismos, como el Banco de Mendoza, el Instituto Financiero Agrario y el Banco de Previsión Social ${ }^{32}$ De igual modo, las soluciones debían buscarse también en el seno de la vitivinicultura porque "no cabe duda de que la formación de cooperativas zonales entre los pequeños viñateros y el otorgamiento de créditos específicos para la construcción de vasijas, son los medios más eficaces para terminar con esa situación”. Asimismo, la plantación de cepas de calidad y el control estatal en las zonas de elaboración, fraccionamiento, distribución y comercialización eran considerados prioritarios. ${ }^{33}$ No obstante, las cooperativas aún representaban un porcentaje menor de la producción agroindustrial: de 1001 establecimientos industriales que elaboraron vino en Mendoza en 1964, 24 correspondían a cooperativas, las cuales aportaban $5.5 \%$ del total de vino elaborado 34

El único caso comparable con el de Bodegas Giol en Argentina es el de la Cavic. Esta sociedad de economía mixta fue creada en 1964 con participación compulsiva y mayoritaria de los productores vitícolas 35 y con el consentimiento de la Federación de Viñateros ${ }^{36}$ La misma había sido organizada sobre la base de la antigua Bodega del Estado, que, a su vez, había sido creada en 193237 durante la segunda gestión gubernamental del líder bloquist 38 Federico Cantoni, y que, si bien había estado destinada a la elaboración de vinos de los pequeños viñateros sin bodega, sólo había sido utilizada como depósito 39 Para que la Corporación alcanzara una capacidad de elaboración de 1000000 de hl de vino -con lo cual se convertiría en uno de los establecimientos

${ }^{31}$ Gobierno de Mendoza ([1965], s. p.).

${ }^{32}$ Discursos de Francisco Gabrielli en los actos de proclamación y transmisión del mando (Gobierno de Mendoza, 1963, pp. 12-14).

${ }^{33}$ Gobierno de Mendoza ([1965], s. p.).

${ }^{34}$ En los registros de la Dirección General de Industrias de Mendoza, no se han podido identificar 45 bodegas de Guaymallén, por lo cual estos números podrían ser ligeramente mayores. Dirección General de Industrias de Mendoza, Elaboración Vinícola Año 1964 (inédito).

${ }^{35}$ Ley de la Provincia de San Juan 3019, aprobada el 6 de febrero de 1964.

${ }^{36}$ Los Andes, 25 de enero de 1964.

${ }^{37}$ Ley de la Provincia de San Juan 439, sancionada el 25 de febrero de 1932. Los Andes, 25 de marzo de 1964.

${ }^{38}$ El Partido Bloquista fue un partido político provincial que había nacido de la separación de la Unión Cívica Radical entre 1916-1922, durante la presidencia de Hipólito Yrigoyen.

${ }^{39} \mathrm{El}$ primer cuerpo de la bodega tenía una capacidad de almacenamiento de 250000 hl; en octubre de 1933 trabajó al máximo de esa capacidad, $500000 \mathrm{hl}$. 
vitivinícolas más grandes del mundo-, se encaró su remodelación ${ }^{40}$ Según el gobernador de San Juan, Leopoldo Bravo: "la Bodega del Estado, en cuyo manejo y administración tendrán parte activísima los productores, y que contará con apoyo oficial por la finalidad económico-social a que estará dedicada, comprará uva en la próxima vendimia, como así, también, vino. Y esa acción será lo suficientemente saludable para estimular un alza en los precios...”. Otro de los objetivos de la firma sería contribuir a "la integración del productor vitícola a las distintas etapas del complejo vitivinícola que termina en la comercialización del producto elaborado" ${ }^{41}$ Para ello, se pensaba, además, obtener recursos para comprar uvas por parte de instituciones financieras, sancionar una ley de expropiación del uso y goce de vasija vinaria y mejorar la calidad del vino con base en lo típico, es decir sin interferir con las producciones de otras zonas. La idea que estaba detrás era asegurar a los pequeños viticultores un precio remunerativo de la uva y transformar la estructura económica, avanzando con la ayuda del crédito público en la integración vertical; este era el mismo propósito que el gobierno de Gabrielli había establecido en su programa económico para la empresa vitivinícola estatal. Sin embargo, los conflictos entre el órgano directivo de la corporación y el gobierno sanjuanino - que le facilitaba asistencia crediticia con garantía estatal- coadyuvaron a la temprana intervención por parte del gobierno nacional durante la presidencia de facto del general Onganía, de modo que su accionar y permanencia en el mercado vitivinícola local fueron mucho menores a las de Bodegas Giol (Olguín, 2013a).

En el caso de Giol, su transformación requerida para adoptar una función de promoción de la integración vertical y de regulación de precios incluía el cambio del régimen jurídico. Gabrielli -al igual que había hecho su par Evans veinte años antes- se propuso modificarlo en una coyuntura de acumulación de reservas vínicas. En efecto, la sobreoferta se tradujo en un pronunciado descenso en los precios reales del vino -esto es, expresados en moneda constante- entre 1962 y 1964 (véanse gráficas 1 y 2). La previsión de una reducción del consumo per cápita, al estimarse que el mercado interno estaba al borde de la saturación y, por lo tanto, de alcanzar el máximo histórico, ensombrecía aún más las perspectivas de la agroindustria.

A principios de 1964, el gobierno creó una comisión de abogados con la misión de elaborar un proyecto de ley que estableciera un nuevo estatuto social, bajo tres premisas: la participación mediante la emisión de acciones de todos los sectores interesados (viñateros sin bodega, contratistas, bodegueros trasladistas, empleados y obreros de la empresa y particulares); la elección de los directores por grupos, donde cada sector designaría un número de representantes independientemente del capital suscrito por cada uno de ellos, y el control de la política de la empresa por parte del gobierno. ${ }^{42}$ Estos requerimientos fueron el alma del proyecto enviado a la legislatura el 29 de octubre para transformar a Bodegas Giol en una sociedad de economía mixta, un régimen jurídico que ya había sido utilizado por los gobiernos demócratas para crear el Banco de Mendoza (1933) y la Sociedad Anónima Corporación Mixta de Fruticultores (1941) (Olguín, 2015a)43

\footnotetext{
${ }^{40}$ En sólo 61 días el depósito de la Bodega del Estado fue transformado en una bodega. La nueva bodega contaba con cuatro moliendas, con fermentadores continuos con una capacidad de 750000 litros cada uno, lo que permitió procesar una cuarta parte de la producción total. Bataller y Mendoza (1999, p. 64). El primer directorio comenzó a funcionar el 26 de marzo de 1964. Los Andes, 25 de marzo de 1964.

${ }^{41}$ Entrevista realizada a Leopoldo Bravo (10 de diciembre de 1963). Los Andes.

${ }^{42}$ La Palabra, 30 de enero de 1964.

${ }^{43}$ El texto completo del proyecto de ley se puede consultar en Diario de Sesiones (periodo 1964-1965, pp. 17681785). Mendoza: Imprenta Oficial. La firma configuraría una persona jurídica privada que se regiría por las disposiciones del estatuto y las de la ley nacional 12.962 (decreto-ley 15.349/1946).
} 
Sin embargo, el bloque de la Unión Cívica Radical del Pueblo (en adelante UCRP) ${ }^{44}$ tres meses antes que el poder ejecutivo, presentó un proyecto de ley para convertir a Bodegas Giol en una empresa estatal, previa expropiación de las acciones por parte del ejecutivo y la disolución de la sociedad anónima, cuyos activos y pasivos serían transferidos a la nueva Bodegas y Viñedos Giol, Empresa Estatal, Industrial y Comercial ${ }^{45}$ La entidad se ejercería como una persona jurídica de derecho privado, con autarquía administrativa y económica y tendría un capital inicial de m\$n 1 000 millones. Sus objetivos eran idénticos a los de la propuesta oficial, con un agregado colocado en primer término: "cumplir, esencialmente, la función reguladora de nuestra industria vitivinícola". La firma costearía sus actividades con recursos propios y con los que le acordara la ley en forma extraordinaria y elevaría su presupuesto anual a los poderes ejecutivo y legislativo, al sólo efecto de su conocimiento. La integración del directorio fue el aspecto más novedoso: el presidente y tres directores serían elegidos por el poder ejecutivo con acuerdo del Senado y otros tres serían elegidos por el pueblo en elecciones directas.

Los argumentos discutidos en torno a la iniciativa de la UCRP mostraron las posturas locales de cada fuerza política en relación con las empresas públicas. El proyecto -que sería aprobado el 28 de noviembre de $19644^{46}$ fue tratado por tres comisiones en cada una de las Cámaras 47 que aconsejaron su aprobación, exhibiendo el acuerdo concertado entre la UCRP y los llamados partidos neoperonistas -Partido Blanco y Tres Banderas- -48 para convalidar la opción de la empresa estatal. El informe del despacho en mayoría fue presentado en el Senado por el principal autor del proyecto, Alejandro Manzur, político de carrera, quien transparentó los motivos ideológicos y las coyunturas política y económica que lo sustentaban. Explicó que los radicales tenían "la obligación de advertir que con esta empresa se puede dar la solución, convirtiéndola en ente regulador, para defensa de nuestros pequeños productores, y con trascendencia a todo el aspecto socioeconómico de la Provincia".

Paradójicamente, el Partido Demócrata de Mendoza votó a favor del proyecto opositor frente al rechazo unánime de su propuesta. Guillermo Mosso, un político vinculado con los emporios vitivinícolas de la época, en la Cámara Baja, sostuvo que la transformación de Bodegas Giol en una empresa estatal permitiría terminar con la "ficción de la sociedad anónima”, donde coexistían organismos de derecho privado (asambleas, directorio y sindicatura) y fines públicos (regulación de un mercado, precio sostén, etc.). Se podría así superar la falta de control con "el gran adelanto que proporcionaba la ley" de someterla al Tribunal de Cuentas de la provincia y allegar recursos a la sociedad mediante el presupuesto para contribuir a su saneamiento financiero. Este último aspecto,

\footnotetext{
${ }^{44}$ La Unión Cívica Radical se dividió en la interna por la candidatura a la presidencia de 1957 en Unión Cívica Radical Intransigente, liderada por Arturo Frondizi, y Unión Cívica Radical del Pueblo, conducida por Ricardo Balbín. En Mendoza, la mayor parte del radicalismo se volcó al balbinismo, cuyos seguidores participaron activamente del gobierno de facto, lo cual fue evitado por los frondizistas en vistas de un acercamiento con Perón.

${ }^{45}$ Sobre el debate del proyecto de ley, véase Legislatura de Mendoza, Diario de Sesiones, periodo 1964-1965, 20 y 23 a 26 de noviembre de 1964, pp. 2.216-2.259; y H. Cámara de Diputados, Diario de Sesiones, periodo 1964, 25 a 30 de noviembre de 1964, pp. 3.346-3.649.

${ }^{46}$ Ley provincial 3.137, en Boletín Oficial de la Provincia de Mendoza, 18 de diciembre de 1964.

${ }^{47}$ En la Cámara de Senadores el proyecto fue tratado por las comisiones de Legislación y Asuntos Constitucionales, de Industria y Comercio y de Hacienda y Presupuesto y, en la Cámara de Diputados, en las de Agricultura e Industria, de Legislación y Asuntos Constitucionales y de Hacienda y Presupuesto.

${ }^{48}$ El neoperonismo fue una corriente política impulsada por algunos dirigentes que, a partir de 1955 , defendieron la doctrina justicialista desde la proscripción, cuestionaron el verticalismo del Partido Justicialista y formaron partidos para participar de los procesos electorales, véase Álvarez (2007).
} 
que implicaba la estructuración futura de los mecanismos que permitieran dotar de recursos a la firma (impuestos, letras de tesorería, bonos, títulos, etc.), constituyó una condición esencial del voto demócrata.

El bloque neoperonista mostró una posición unificada en ambas cámaras y propuso la participación en el directorio de empleados de Bodegas Giol o de la Federación de Obreros y Empleados Vitivinícolas y Afines, que reunía 29 sindicatos en todo el país. Tal modificación fue rechazada por la bancada radical. Si bien el radicalismo no esgrimió las razones de su negativa, es probable que su veto se basara en prevenciones de carácter político. La gran influencia que el Partido Comunista de Maipú tenía en los trabajadores de Bodegas Giol, la identificación de la Federación de Obreros y Empleados Vitivinícolas y Afines con el peronismo y el avance de la línea dura del sindicalismo a nivel nacional, que había tenido su punto más álgido con la toma de fábricas en mayo y junio de 1964, pueden haber constituido un obstáculo para que la UCRP aceptara la representación de los trabajadores en el directorio de la empresa 49

La forma jurídica "empresa estatal" marcó el rumbo de Bodegas Giol hasta su liquidación en 1991, el cual se mantuvo inescindible en los vaivenes de la vida institucional argentina, que alternó gobiernos civiles y militares; los primeros, proclives al intervencionismo económico, los segundos, al liberalismo económico. El establecimiento de estrategias empresariales de largo plazo, tanto en relación con funciones de regulación como de integración de productores, se transformó entonces en un objetivo inalcanzable luego del golpe de Estado de 1966. En buena medida, esta experiencia a escala provincial da cuenta, como advirtió Labrador (2016, p. 13), de la polarización entre capitalismo y socialismo que surgió a partir de los prejuicios relativos a la regulación y la propiedad públicas en América Latina durante el siglo xx.

\section{Conclusiones}

El artículo se propuso estudiar los planes gubernamentales para Bodegas y Viñedos Giol, firma líder del mercado vitivinícola argentino, en el tercer cuarto del siglo xx. Se enfocó en los planes económicos y financieros que propiciaron su compra por parte del estado de Mendoza en 1954 y en aquellos que promovieron su transformación en un instrumento de regulación de precios e integración vertical de productores en 1964. A partir de un enfoque de historia de empresas y de la consulta de un variado conjunto de fuentes públicas y privadas, se ofrecen nuevas evidencias sobre Bodegas Giol como instrumento de desarrollo económico provincial, en el marco del avance del Estado sobre el control de empresas industriales en Argentina.

Bodegas Giol constituyó el instrumento más drástico y controvertido de intervención estatal en 150 años de historia de la agroindustria vitivinícola argentina. Su estructura y cultura organizacional, basadas en la innovación tecnológica y gerencial, fueron utilizadas para avanzar en la diversificación de la matriz productiva de Mendoza y regular el mercado vitivinícola. El proyecto de la cooperativa estatal y el experimento financiero, elaborado en los comienzos de la década de 1950 por funcionarios de alto rango de los ministerios de Economía y Hacienda de la provincia, constituyó una de las bases del programa de la tercera gestión de gobierno peronista. En un contexto de ajuste fiscal y restricción presupuestaria, la organización se ocuparía de integrar la cadena vitivinícola, frutícola y hortícola en sus etapas agrícola, industrial y comercial, posibilitando, de este modo, el desarrollo estable y sostenido de las agroindustrias. En un futuro, parte de las acciones

${ }^{49}$ Entrevista a Luis Bobillo realizada por Patricia Olguín, 18 de noviembre de 2011, Mendoza. 
de Bodegas Giol se vendería a cooperativas, pequeños productores y trabajadores de la firma para posibilitar su autogestión en sociedad con el Estado. Asimismo, a partir de dicha firma vitivinícola, se crearían sociedades subsidiarias de capital mixto con el fin de poner en marcha proyectos agrícolas, comerciales, industriales y sociales, cuyos dividendos financiarían un ambicioso plan de obras públicas. Sin embargo, la caída del peronismo frustró su creación.

El proyecto de la entidad promotora y reguladora de la agroindustria vitivinícola mendocina, diseñado por Francisco Gabrielli y sus colaboradores en los inicios de la década de 1960, contribuiría a lograr los principales objetivos del programa de gobierno en relación con la vitivinicultura, que consistían en estabilizar los ciclos económicos, integrar verticalmente la cadena, aumentar las exportaciones y elaborar vinos de alta calidad enológica. Bodegas Giol intervendría en los mercados de uvas y vinos de Mendoza en las etapas recesivas por medio de operaciones de compra y venta, y prestaría el servicio de elaboración a viñateros sin bodega; todo ello ocurriría mientras se avanzaba en la integración vertical y la diversificación productiva de la economía provincial sobre la base del desarrollo de industrias de base minera y agraria. Para ello, Gabrielli consideró necesaria la participación de todos los sectores interesados y la concurrencia del ahorro público y privado. Propuso modificar la forma jurídica de la empresa y convertirla en una sociedad de economía mixta, en la cual el directorio estaría formado por representantes de cada grupo, pero la política empresarial quedaría bajo el control del gobierno. A pesar del aparente consenso entre los sectores políticos y empresariales, el proyecto oficial fracasó en la legislatura provincial frente a otro elaborado por la UCRP, que consiguió convertir a Bodegas Giol en una empresa estatal.

Leopoldo Bravo impulsó una iniciativa similar a la de Gabrielli mediante la creación de la sociedad de economía mixta CAvic, aunque su actividad fue mucho más breve. Los requerimientos de crédito público por parte de Bodegas Giol y CAVIC probablemente disminuyeron la disponibilidad de fondos para las cooperativas privadas, así como los incentivos para la integración de pequeños y medianos productores en este tipo de entidades, las cuales continuaron elaborando una porción reducida del total del vino ofrecido en el mercado, a diferencia de la expansión que registraron en España durante el mismo periodo.

En consecuencia, los resultados obtenidos indican que las funciones asignadas a Bodegas Giol mantuvieron un extendido consenso tanto en las gestiones de gobierno peronistas como en las demócratas, reflejando coincidencias en los objetivos de política económica. En efecto, la empresa conservó el interés como instrumento estatal de diversificación de la estructura productiva, de integración vertical de los pequeños y medianos productores y de estabilización de los mercados de uvas y vinos, mientras las tendencias a la especialización productiva, la sobreproducción de vinos, las asimetrías entre los actores de la cadena vitivinícola y el avance del Estado en el control de empresas industriales -incluso en actividades económicas regionales- fueron elementos comunes que se mantuvieron vigentes en un clima de elevada confrontación política e inestabilidad de los indicadores económicos.

Las especificidades de los proyectos dependían de las modalidades de constitución, las cuales fueron influidas por la trayectoria académica y profesional de los funcionarios que ocuparon los principales cargos en el poder ejecutivo provincial (gobernadores y ministros). En efecto, la propuesta vinculada a la creación de una cooperativa, realizada por Mario Ceresa, tenía sus antecedentes en su etapa de estudiante universitario de agronomía y fue influida por su paso por la administración pública durante los gobiernos conservadores. La propuesta más novedosa referida a la puesta en marcha de empresas con fines financieros de Benedicto Caplán, también estaba vinculada a su formación académica. El proyecto de transformar a la firma en un instrumento de 
integración vertical y de regulación de precios, cuyo principal promotor fue el propio Francisco Gabrielli, que confiaba en la asociación entre el Estado y el sector privado, tenía sus raíces en el conocimiento sobre empresas vitivinícolas familiares y la burocracia estatal y en una concepción política basada en la eficiencia y el orden en la gestión pública. Frente a su fracaso en el recinto legislativo, el proceso de negociación desarrollado entre los sectores neoperonistas y la ucRP que terminó en la estatización de Bodegas Giol, privilegió el control político y financiero de la firma. A pesar de los vínculos mantenidos con el sector vitivinícola, sus impulsores habían desarrollado una carrera política, y no tanto una profesional.

La experiencia de Bodegas Giol muestra que, efectivamente, algunos matices fueron posibles en la polarización entre capitalismo y socialismo que tuvo lugar en los debates relativos a la regulación y propiedad públicas en Latinoamérica en el siglo xx. Asimismo, ilustra que esos matices estuvieron dados por las políticas, pero, sobre todo, por las trayectorias de quienes las diseñaron y ejecutaron.

\section{Lista DE REFERENCIAS}

Álvarez, Y. (2007). De la proscripción al poder: historia, evolución y luchas del peronismo en Mendoza, 1955-1973. Mendoza: Universidad Nacional de Cuyo.

AzPiazu, D. y Basualdo, E. (2001). El complejo vitivinícola argentino en los noventa: potencialidades y restricciones. Buenos Aires: Comisión Económica para América Latina y el Caribe.

BALÁn, J. (1978). Una cuestión regional en la Argentina: burguesías provinciales y el mercado nacional en el desarrollo agroexportador. Desarrollo Económico, 18(69), 49-87. DOI: 10.2307/ 3466376

Balán, J. y López, N. (1977). Burguesías y gobiernos provinciales en la Argentina: La política impositiva de Tucumán y Mendoza entre 1873 y 1914. Desarrollo Económico, 17(67), 391435. DOI: $10.2307 / 3466640$

BARBERo, M. (2006). La historia de empresas en la Argentina: trayectoria y temas en debate en las últimas dos décadas. En J. Gelman (ed.), La historia económica argentina en la encrucijada. Balances y perspectivas (pp. 153-169). Buenos Aires: Prometeo Libros/Asociación Argentina de Historia Económica.

Barbero, M. I. y Jacob, R. (eds.) (2008). La nueva historia de empresas en América Latina y España. Buenos Aires: Temas.

BARRIO, P. (2002). Una crisis de la vitivinicultura mendocina a principios del siglo Xx (1901-1903). En XVIII Jornadas de Historia Económica. Mendoza: Universidad Nacional de Cuyo.

Barrio, P. (2010). Hacer vino: empresarios vitivinícolas y Estado en Mendoza, 1900-1912. Rosario: Prohistoria Ediciones.

BeLINI, C. (2009). La industria peronista. 1946-1955: políticas públicas y cambio estructural. Buenos Aires: Edhasa.

Belini, C. y Rougier, M. (2008). El Estado empresario en la industria argentina. Conformación y crisis. Buenos Aires: Manantial.

BirentzWaig, A. E. (ed.) (1982). Relevamiento estadístico de la economía argentina 1900-1980. Buenos Aires: Banco de Análisis y Computación.

Caplán, B. (1955). Finanzas públicas. Buenos Aires: Oresme.

CAPLÁn, B. (1956). Pan y libertad. Dos aspiraciones milenarias que unirán al mundo dentro de un programa práctico de gobierno para la felicidad de los pueblos. Buenos Aires: Oresme. 
Caplán, B. (1957). Giol. Un experimento financiero. Buenos Aires: s. e.

Cerdé, J. M. (2017). Desarrollo del cooperativismo vitivinícola en la provincia de Mendoza. Rivar, 4(13), 34-54.

Ceresa, M. C. D. (1943). La cooperación en la industria vitivinícola. Contribución para resolver la crisis vitivinícola nacional. Revista de la Facultad de Agronomía, 25, 215-224.

Ceresa, M. C. D. (1953). Acción económica del gobierno de Mendoza en el segundo plan quinquenal. En Conferencia pronunciada por el ministro de Economía de la provincia ante los jefes, funcionarios y empleados superiores de las dependencias del ministerio (pp. 25-27). Mendoza: Imprenta Oficial.

Coria, L. A. (2010). El boom vitivinícola de Mendoza (Argentina) y su impacto espacial interno (1883-1914). Estudios Avanzados, 14, 145-173.

Cortés, R. (2003). Economía Política del Peronismo (1946-1955). Anuario del CEH, 2-3, 211 222.

Cuddra, E. (1998). Gobernador Carlos Horacio Evans. Mendoza: Inca.

DÁvila, C. (2013). The Current State of Business History in Latin America: Business History in Latin America. Australian Economic History Review, 53(2), 109-120. DOI: 10.1111/aehr.12006

DíAz, E. (1982). Crisis vitivinícola. Estudios y propuestas para su solución. Anexo legislativo. Mendoza: Idearium.

Evans, C. (1954). Mensaje 1953-1954. Mendoza: Imprenta Oficial.

Evans, C. (1955). Mensaje 1954-1955. Mendoza: Imprenta Oficial.

Fleming, W. J. (1979). The cultural determinants of entrepreneurship and economic development: A case study of Mendoza Province, Argentina, 1861-1914. The Journal of Economic History, 39(1), 211-224. Dor: 10.1017/S0022050700096406

García, R. (2007). Historia empresarial e historia económica en Argentina: un balance a comienzos del siglo XIX. Bogotá: Universidad de los Andes.

Gerchunoff, P. y Antúnez, D. (2002). De la bonanza peronista a la crisis de desarrollo. En J. C. Torre (ed.), Nueva historia argentina. Los años peronistas (1943-1955) (pp. 125-206). Buenos Aires: Sudamericana.

Gobierno de Mendoza (1953). Difusión del segundo Plan Quinquenal. Mendoza: Imprenta Oficial.

Gobierno de Mendoza (1963). Discursos pronunciados por s. e. el señor gobernador de la provincia ing. Francisco J. Gabrielli en los actos de proclamación y transmisión del mando. Mendoza: Imprenta Oficial.

Gobierno de Mendoza (1965). Mendoza en marcha. Un año de gobierno 1963 -12 de octubre- 1964. Mendoza: Imprenta Oficial.

Gobierno de Mendoza (1967). Anuario. Instituto de Investigaciones Económicas. Mendoza, Argentina. 1964'65. Mendoza: Imprenta Oficial.

Gobierno de Mendoza (1969). Anuario. Instituto de Investigaciones Económicas. Mendoza, Argentina. 1966’68. Mendoza: Imprenta Oficial.

Gobierno de Mendoza. Instituto de Investigaciones Económicas y Tecnológicas (1952). Anuario. Sintesis estadística y geográfico-económica. Mendoza: s. e.

Guajardo, G. (2015). La empresa pública y sus definiciones en el largo plazo. En G. Gujardo y A. Labrador (eds.), La empresa pública en México y en América Latina: entre el mercado y el Estado (pp. 23-35). México: Universidad Nacional Autónoma de México/Instituto Nacional de Administración Pública. 
Guajardo, G. y Labrador, A. (eds.) (2015). La empresa pública en México y en América Latina: entre el mercado y el Estado. México: Universidad Nacional Autónoma de México/Instituto Nacional de Administración Pública.

Instituto de Investigaciones Económicas y Tecnológicas (1962). Anuario 1961. Mendoza: Imprenta Oficial.

Instituto Nacional de Estadísticas y Censos (2015). Serie histórica del índice de precios internos al por mayor (IPIM), base 1993=100, desde 1956 hasta 1995, nivel general. Recuperado de www.indec.gov.ar

Instituto Nacional de Vitivinicultura (1987). Síntesis básica de estadística vitivinícola argentina años 1960-1986. Mendoza: Instituto Nacional de Vitivinicultura.

Junta de Estudios Históricos de Mendoza (1996). Historia contemporánea de Mendoza a través de sus gobernadores. Mendoza: Autor.

Labrador, A. (2015). Introducción. En G. Guajardo y A. Labrador (eds.), La empresa pública en México y en América Latina: entre el mercado y el Estado (pp. 13-22). México: Universidad Nacional Autónoma de México/Instituto Nacional de Administración Pública.

Mallon, R. y SourroullLe, J. (1973). La política económica en una sociedad conflictiva: el caso argentino. Argentina: Amorrortu.

Martín, P. y Comín, F. (Eds.). (1990). Empresa pública e industrialización en España. Madrid: Alianza.

Mateu, A. M. (2002). La vitivinicultura mendocina: ¿una opción dura y no demorada en la periferia de la periferia? (1870-1920). En Actas de las XVIII Jornadas de Historia Económica. Mendoza.

Mateu, A. M. (2014). Las posturas oscilantes de una centenaria corporación vitivinícola frente a la regulación de la industria, Mendoza, 1930-1955. América Latina en la Historia Económica, 21(1), 134-143. DOI: 10.18232/alhe.v21i1.562

Mateu, A. M. y Olguín, P. E. (2006). El problema no es intervenir sino cómo. Las posturas de la AVA frente al gobierno peronista. En XX Jornadas de Historia Económica. Argentina: Universidad de Mar del Plata.

Mateu, A. M. y Stein, S. (eds.) (2008). El vino y sus revoluciones: una antología histórica sobre el desarrollo de la industria vitivinícola argentina. Mendoza: Universidad Nacional de Cuyo.

Medina-Albaladejo, F. (2016). Intervención estatal del sector vitivinícola español durante el franquismo: las bodegas cooperativas. En N. M. Girbal-Blacha, M. I. LóPez y S. R. DE MendonçA (eds.), Agro y política a uno y otro lado del Atlántico: franquismo, salazarismo, varguismo y peronismo (pp. 31-54). Buenos Aires: Imago Mundi.

Micale, A. (1999). Historia institucional de Mendoza (segunda parte). Historia del Ministerio de Economía. Mendoza: Ediciones Culturales de Mendoza.

OlarRa, R. (1968). Evolución monetaria argentina. Buenos Aires: Eudeba.

Olguín, P. E. (2010). Bodegas y Viñedos Giol, de sociedad colectiva a empresa estatal (Mendoza, 1898-1954). En XXII Jornadas de Historia Económica. Argentina: Universidad Nacional de Río Cuarto.

Olguín, P. E. (2012). Estado, empresas y regulación. La experiencia de las entidades reguladoras del mercado vitivinícola de Mendoza (Argentina, 1914-1943). Revista de Historia Industrial, 21(49), 77-110.

Olguín, P. E. (2013a). Giol y CAVIC: la experiencia reguladora de dos empresas públicas en el mercado vitivinícola cuyano (1964-1988). En IV Jornadas de Historia de la Industria y los Servicios. Argentina: Universidad de Buenos Aires. 
Olguín, P. E. (2013b). La experiencia de una empresa pública en la regulación del mercado vitivinícola de Mendoza: expansión, declinación y privatización de Bodegas y Viñedos Giol. En M. Rougier (ed.), Estudios sobre la industria argentina. Carapachay: Lenguaje Claro.

Olguín, P. E. (2015a). Estado, empresas y desarrollo económico: las empresas públicas agroindustriales en la Provincia de Mendoza. En A. Regalsky y M. Rougier (eds.), Los derroteros del Estado empresario en la Argentina. Siglo xx. Buenos Aires: Universidad Nacional de Tres de Febrero.

Olguín, P. E. (2015b). Vender vino: la compleja cadena de intermediación entre el bodeguero y el consumidor final (Argentina, 1943-1970). En A. Lluch y J. L. MartiRéN (eds.), Las manos visibles del mercado: intermediarios y consumidores en la Argentina. Rosario: Prohistoria Ediciones/Universidad Nacional de La Pampa.

Olguín, P. E. (2016). Las conexiones entre dos mundos vitivinícolas (Argentina e Italia). Las inversiones de Juan Giol en San Polo di Piave (1912-1930). En XXV Jornadas de Historia Económica. Argentina: Universidad Nacional de Salta.

Olguín, P. E. y Mellado, V. (2006). La crisis de la vitivinicultura en los años 30. Alejandro Bunge y sus diagnósticos sobre las políticas económicas de regulación. En XX Jornadas de Historia Económica. Argentina: Universidad de Mar del Plata.

Ospital, M. S. (2013). Empresarios vitivinícolas y políticas públicas. Argentina (1905-1943). En N. M. Girbal-Blacha y S. R. Mendonça (eds.), Corporaciones agrarias y políticas públicas en América Latina (pp. 21-36). Rosario: Prohistoria.

Ospital, M. S. y Cerdé, J. M. (2016). Intervención estatal y agroindustria vitivinícola: el caso de la Junta Reguladora de Vinos. H-Industria, 10(18), 58-78.

Perón, J. D. (1952). Perón anuncia el plan económico de 1952 y los precios de la cosecha. Buenos Aires: Presidencia de la Nación.

Plotkin, M. B. y Zimmermann, E. A. (eds.) (2012). Las prácticas del Estado: política, sociedad y elites estatales en la Argentina del siglo Xx. Buenos Aires: Edhasa.

Regalsky, A. M. (2010). De Buenos Aires a las provincias: la formación de una empresa pública nacional de saneamiento urbano en la Argentina. Obras sanitarias de la nación, 1891-1930. Desarrollo Económico, 50(199), 455-482.

Regalsky, A. y Rougier, M. (2015). Los derroteros del Estado empresario en la Argentina. Siglo XX. Buenos Aires: Universidad Nacional de Tres de Febrero.

Richard, R. A. (1998). Poder, economía y espacio en Mendoza, 1850-1900: del comercio ganadero a la agroindustria vitivinícola. Mendoza: Universidad Nacional de Cuyo.

Richard, R. A. (2000). Modelos vitivinícolas en Mendoza (Argentina): desarrollo y transformaciones en un periodo secular, 1870-2000. História Econônica \& História de Empresas, 3(1), 111 148.

Richard, R. A. (2008). Cuando el pasado nos acompaña. La vitivinicultura capitalista en Mendoza y San Juan en clave histórica, 1870-2006. En J. Balsa, G. Mateo, M. S. Ospital y Universidad Nacional de Quilmes (eds.), Pasado y presente en el agro argentino (pp. 43-64). Buenos Aires: Lumiere.

Richard, R. A. y Pérez, E. (1994). El proceso de modernización de la bodega mendocina (18601915). Ciclos, 7, 119-155.

Rougier, M. (ed.) (2007). Políticas de promoción y estrategias empresariales en la industria argentina, 1950-1980. Buenos Aires: Ediciones Cooperativas. 
Rougier, M. (ed.) (2010). Estudios sobre la industria argentina. Políticas de promoción y estrategias empresariales. Buenos Aires: Lenguaje Claro.

Rougier, M. (2011). Estado y empresarios de la industria del aluminio en la Argentina: el caso ALUAR. Bernal: Universidad Nacional de Quilmes.

Rougier, M. (ed.) (2013). Estudios sobre la industria argentina. Carapachay: Lenguaje Claro.

Schvarzer, J. (2006). La industria argentina en la perspectiva de la historia. En J. Gelman (ed.), La historia económica argentina en la encrucijada: balances y perspectivas. Buenos Aires: Prometeo Libros/Asociación Argentina de Historia Económica.

Siккіnк, K. (2009). El proyecto desarrollista en la Argentina y Brasil Frondizi y Kubitschek. Buenos Aires: Siglo XXI/Iberoamericana.

SPINELli, M. E. (2005). Los vencedores vencidos: el antiperonismo y la "revolución libertadora”. Buenos Aires: Biblos.

TCach, C. y Rodríguez, C. (2006). Arturo Illia: un sueño breve: el rol del peronismo y de los Estados Unidos en el golpe militar de 1966. Buenos Aires: Edhasa. 